\title{
Evaluation of Peripapillary and Subfoveal Choroid Thickness in Asymptomatic Carotid Artery Stenosis
}

This article was published in the following Dove Press journal: Clinical Ophthalmology

\author{
Ece Turan-Vural ${ }^{1}$ \\ Unsal Vural ${ }^{2}$ \\ 'Ophthalmology Clinic, Haydarpasa \\ Numune Training and Research Hospital, \\ Istanbul, Turkey; ${ }^{2}$ Cardiovascular Surgery \\ Clinic, Siyami Ersek Training and \\ Research Hospital, Istanbul, Turkey
}

\begin{abstract}
Objective: In this study, it aims to investigate the effect of asymptomatic carotid artery stenosis on peripapillary and subfoveal choroid thickness using enhanced depth imaging optical coherence tomography.
\end{abstract}

Patients and Methods: While investigating for coronary artery disease, 76 patients with asymptomatic carotid artery stenosis and 35 patients with normal carotid artery (total $=111$ ) were evaluated. Patients according to the degree of stenosis were divided into four categories as non-stenosis $(n=35)$, mild $(n=26)$, moderate $(n=27)$ and severe stenosis $(n=23)$. Subfoveal and peripapillary choroid thickness, ocular perfusion and intraocular pressures of all patients were measured using a Fourier-domain optical coherence tomography after general ophthalmological examination. In addition, hypertension, hyperlipidemia, and whether there is a relationship between smoking status and choroid thickness was compared.

Results: As the degree of carotid artery stenosis increased, subfoveal and peripapillary choroidal thickness decreased significantly. However, no changes were detected in ocular perfusion and intraocular pressure values $(\mathrm{p}=0.935, \mathrm{p}=0.519)$. Decrease in peripapillary and subfoveal choroid thickness values was found to be particularly between the group with severe stenosis and the group with control and mild stenosis $(p=0.003, p=0.001)$. In addition, as the degree of carotid stenosis increased in patients with hypertension and smoking, peripapillary choroid thickness was found to be thinner $(\mathrm{p}=0.003)$.

Conclusion: We believe that the possibility of carotid artery stenosis should be considered in cases with decreased choroid thickness. In addition, we think that even if it is asymptomatic, in cases with severe carotid stenosis, in the presence of choroidal thinning, a chance of surgical intervention should be given to the stenosis.

Keywords: carotid artery stenosis, subfoveal choroid thickness, peripapillary choroid thickness, enhanced depth imaging optical coherence tomography

\section{Introduction}

Blood supply to the eye and the intraorbital tissues are provided from the ophthalmic artery and partially from the branches of the external carotid artery. ${ }^{1}$ The ophthalmic artery is the first branch of the internal carotid artery (ICA) and, its branches create the central retinal artery and posterior ciliary arteries. ${ }^{1}$ ICA stenosis can cause retinal and choroidal hypoperfusion. Choroidal blood circulation is supplied by short posterior ciliary arteries, long posterior ciliary arteries and anterior ciliary arteries which are the branches of the ophthalmic artery. ${ }^{1}$ The choroid blood circulation has physiological functions such as provision of vascular supply
Correspondence: Ece Turan-Vura Haydarpasa Egitim ve Arastırma Hastanesi Tibbiye Caddesi, Göz Klinigi No: 40, Uskudar/lstanbul 34668, Turkey

Tel +905054004628

Fax +902163377877

Email dreceturan76@gmail.com 
to the anterior optic nerve head and retina, emmetropization, thermoregulation and removal of the waste product. ${ }^{2}$ Therefore, a structurally and functionally healthy choroid vasculature has an important role in the normal function of the macular and peripapillary area.

Ocular hemodynamic changes have become the focus of ophthalmological researchers in recent years. ${ }^{3}$ As is known, ICA stenosis can cause not only nervous system diseases, but also ischemic ocular lesions. It has been suggested by Lawrence and Oderich that when the degree of ICA stenosis is greater than $50 \%$, the incidence of eye symptoms is increased. ${ }^{5}$ Painless temporary vision loss (amaurosis fugax) is one of the most common ocular symptoms. Lyons-Wait et al showed that retinal hemodynamic changes increased 1.8 -fold in patients with ICA stenosis compared to healthy people. Retinal emboli, retinal arterial occlusion, anterior ischemic optic neuropathy, ocular ischemic syndrome or glaucoma are other hemodynamic abnormalities determined in fundus examination. ${ }^{4}$ Besides, it has also been reported that approximately 5\% of patients with severe ICA stenosis have ocular hemodynamic abnormalities. ${ }^{6}$

Ophthalmic artery hypoperfusion can cause retinal and choroidal microcirculation abnormalities. These abnormalities result in inadequate blood perfusion to the inner and outer retinal layers and this condition may cause ischemic ocular lesions. For this reason, not only the retinal blood supply but also the choroidal blood supply situation can be affected by ICA stenosis. ${ }^{3}$ For these reasons, the relationship between choroidal thickness and choroidal circulation has been the subject of important research in the past. ${ }^{7}$

Many articles have been published to show the relationship between changes in choroidal thickness and characteristic ophthalmic pathological changes. Recently, it has been demonstrated by Spaide et al that choroidal thickness could be measured successfully and non-invasively in vivo by using commercially available spectral-domain optical coherence tomography (SD-OCT) devices that used the enhanced depth imaging (EDI) technique. 8 In this study, it was aimed to investigate the effect of asymptomatic ICA stenosis on peripapillary and subfoveal choroid thickness using enhanced depth imaging optical coherence tomography. For this purpose, peripapillary choroidal thickness (PPCT) and subfoveal choroidal thickness (SCT) were measured and compared between patients with asymptomatic but varying degrees of ICA stenosis. In addition, the relationship between the increase in carotid stenosis grade and hypertension, hyperlipidemia and smoking status were analyzed.

\section{Patients and Methods}

This study was performed at Dr. Siyami Ersek Thoracic and Cardiovascular Surgery Center and, Haydarpasa Training and Research Hospital. The study protocol was approved by the Health Sciences University Siyami Ersek Cardiovascular Surgery Hospital Ethics Committee decision dated 16/06/2017 and numbered (Number No: 28,001,928-501.07.08) and the patients were informed in writing. For the methodology of the study, the principles of the World Medical Association Helsinki Declaration made in 1964 were adhered to. The study included 111 patients who applied to the cardiovascular surgery clinic between December 2017 and February 2018, all with coronary artery disease. 76 of these patients had varying degrees of asymptomatic ICA stenosis. The carotid arteries of the other 35 cases were evaluated as normal.

The cases were divided into four groups as followings; Patients with $29 \%$ or less stenosis due to age-related plaques were included in the healthy control group. [I. Group; 35 cases; 10 women; Median age $=71$ (68-80)]. Group with mild stenosis (30-49\% stenosis) [II. Group; 26 cases; 7 females; median age=71 (60-82)]. Group with moderate stenosis (50-69\% stenosis) [III. Group; 27 cases; 10 females; median age=73 (64-80)]. Group with severe stenosis (70-99\% stenosis) [IV. Group; 23 cases; 3 females; median age $=75(65-80)]$.

\section{Subjects}

In echocardiography, patients with ejection fraction due to coronary artery disease above $30 \%$ and whose carotid arteries were evaluated by Doppler ultrasound or CT angiography were included in the study. Eye inclusion criteria were as follows; The patients with no history of ocular disease (except refractive errors myopia or hyperopia \pm 2 $\mathrm{D}$, astigmatism $\pm 1.5 \mathrm{D}$ or presbyopia), the patients with an IOP of greater than $21 \mathrm{mmHg}$, a normal optic disc appearance and the patients with the axial length of less than $24 \mathrm{~mm}$ were included in the study. For each patient, only one eye meeting all the inclusion criteria was included in the study. If both eyes of a patient were eligible for inclusion, then only one eye was randomly included in the study.

Systemic diseases such as Patients with diabetes mellitus, kidney failure, malignancy, autoimmune diseases, hematological diseases, chronic obstructive pulmonary disease, uncontrolled arterial hypertension, transient ischemic attack 
or stroke, and patients who might affect retinal or choroid thickness were also excluded. Eye exclusion criteria were as follows; history or evidence of chorioretinal or vitreoretinal diseases, including age-related macular degeneration, epiretinal membrane, central serous chorioretinopathy, diabetic retinopathy, and macular dystrophy, history of intraocular surgery, trauma, ocular inflammation or topical treatment, best-corrected visual acuity of less than 20/25, evidence of glaucoma, poor image due to cataract.

In the study, controlled arterial hypertension, hypercholesterolemia, and smoking status were also recorded to determine whether they affect the choroid and retinal thickness. The degree of stenosis was graded as (Mild: 30-49\%, Moderate: 50-69\%, Severe stenosis: 70-99\%) and occlusion, according to the recommendations of the Ultrasound Consensus Conference approved by the Association of Radiological Experts, determined by Doppler ultrasound measurement. ${ }^{9}$

All participants underwent a thorough ophthalmic examination. Objective refraction was measured by autorefractometer (Topcon, RK-8800, Tokyo), and best-corrected visual acuity was recorded by using Snellen charts. Biomicroscopic and funduscopic examinations were performed by using a 90 $\mathrm{D}$ lens and intraocular pressure was measured by using a Goldman Applanation Tonometer.

All measurements were made between 9-10 am in the morning to avoid diurnal changes. Blood pressure, axial length, and keratometry were measured using the IOL Master (Carl Zeiss Meditec, Dublin, CA) while sitting in the resting position for both eyes of the patient.

\section{Choroidal Thickness Measurement Protocol}

All measurements were performed by the same technician. The methods for obtaining of enhanced depth imaging OCT images have been reported previously. ${ }^{10,11}$ The images obtained were viewed and measured via the Heidelberg Eye Explorer software (version 0.6.3.2.0; Heidelberg Engineering) contained within the system. The EDI button was activated, and choroid imaging was obtained.

Measurement process was performed manually in a specific area bounded by the outer border of the retinal pigment epithelium and the inner scleral border. The author performed this process in a masked fashion without knowledge of subject information (Figures 1 and 2).

Data obtained by measuring subfoveal and peripapillary choroidal thickness measurements, systolic, diastolic

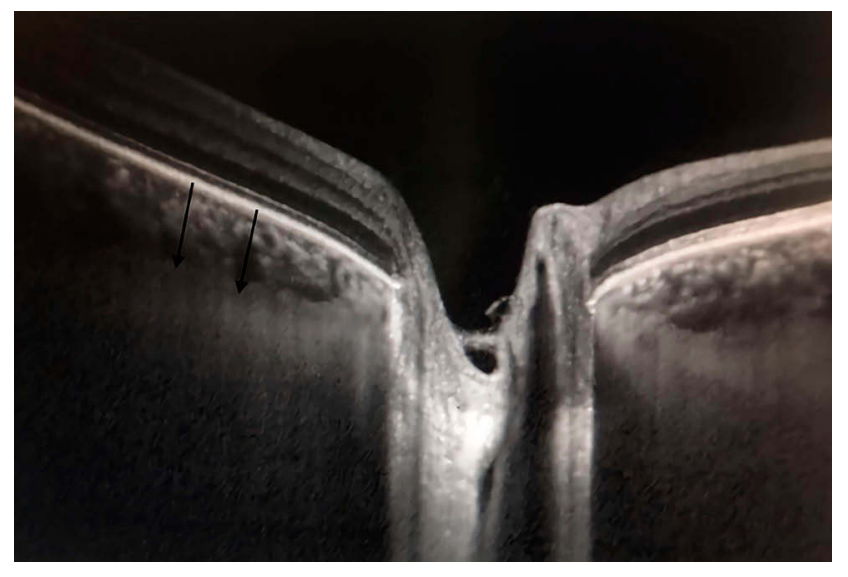

Figure I Manual measurement of PPCT in EDI-OCT image.

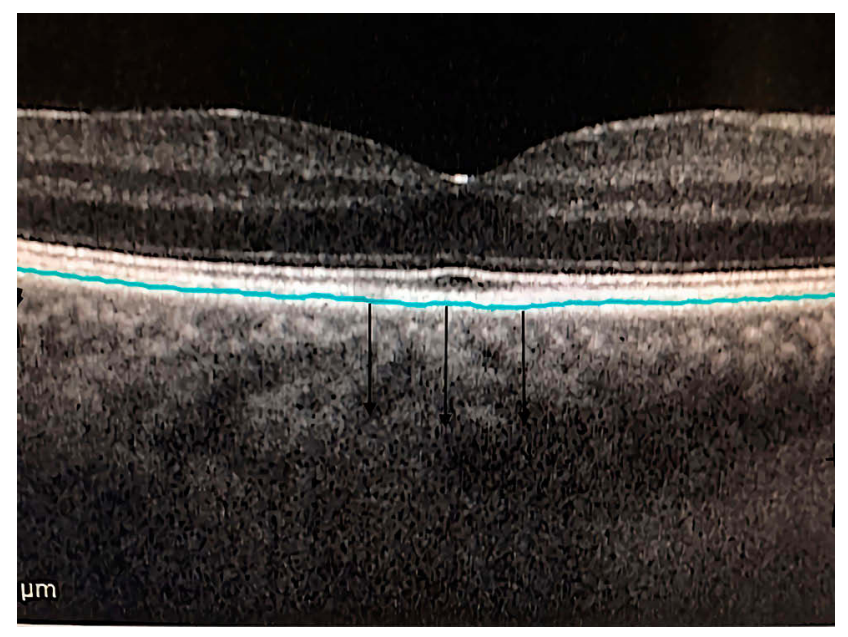

Figure 2 Manual measurement of SCT in EDI-OCT image.

blood pressures, ocular perfusion pressures, and intraocular pressures were taken into statistical evaluation.

\section{Statistical Analysis}

Continuous variables were expressed as mean $\pm \mathrm{SD}$ and maximum-minimum. Categorical variables were expressed as percentages. Shapiro-Wilk normality test was used for normality test. Student's $t$-test was used for the analysis of normally distributed binary groups, and ANOVA was used for the analysis of three or more groups. Mann-Whitney $U$-test was used in non-normally distributed binary groups, and Kruskal-Wallis $H$-test was used in the analysis of three or more groups. Dunn test was used as Post Hoc test in determining the group that caused difference between three or more groups. Spearman correlation test was used for relationship status. Linear regression analysis was used to determine parameters predicting both eye 
findings and carotid stenosis. The sample size was calculated using the $G$ Power ${ }^{\circledR}$ 3.1.9.2 program, with the power of the research over $80 \%$. SPSS Statistics for Windows, (version 19.0; SPSS Inc, Chicago) program was used for analysis. Significance was evaluated at a level of $p<0.05$.

\section{Results}

Demographic and clinical characteristics of the groups are shown in Table 1. No significant relationship was found between the increase in the carotid stenosis of the patients and age, gender, hypertension and smoking ( $p>0.05$; Table 1). When the relationship between cholesterol levels and carotid stenosis was examined, there was no relationship in the control, mild, severe stenosis group, whereas, a moderate relationship was found in the middle stenosis group (Table 1). Considering all cases independent from the groups, a low but significant $(r=0.317 ; \mathrm{p}=0.001)$ relationship was found between the increase in cholesterol level and the degree of carotid stenosis. There was no significant relationship between age and carotid stenosis in any group.

While there was a significant difference between the SCT and PPCT values of the groups $(p=0.003, p=0.001$ respectively), no difference was found between the OPP and IOP values Table 2). In both SCT and PPCT, post hoc analysis revealed that the difference was between the control and mild stenosis groups and the severe stenosis group $(\mathrm{p}=0.043, \mathrm{p}=0.001$ respectively, Table 2, Figure 3). Considering all patients, when the direction and magnitude of the relationship between carotid stenosis grade and SCT and PPCT were analyzed, it was found that SCT and PPCT decreased moderately significantly as ICA stenosis increased $(\mathrm{p}=0.003, \mathrm{r}=-0.28, \mathrm{p}=0.001, \mathrm{r}=-0.47$, respectively, Figure 3).

In order to predict the carotid stenosis degree, when a model was created with the eye findings, it was determined that the model was able to predict the stenosis degree by $33.7 \%$ and this was significant $\left(\mathrm{p}=0.001 ; \mathrm{r}^{2}=0.337\right.$; Durbin Watson $=0.841$, Table 3 ). In the model, it is seen that cholesterol, SCT and PPCT are both significantly related and predictive parameters with the degree of carotid stenosis (Table 3)

Considering all the cases, it can be seen in Table 3 that the increase in cholesterol level and the decrease in SCT and PPCT can predict an increase in the degree of carotid stenosis and other parameters do predict not significantly. It is also seen in Table 3 that the degree of carotid stenosis is not related to other non-predictive parameters.
When the eye findings (SCT, PPCT, IOP, OPP) are compared in patients, with or without hypertension considering all the cases; It was observed that the increase in the degree of stenosis in patients without hypertension did not significantly affect the eye findings $(\mathrm{p}=0.162 ; \mathrm{p}=$ $0.068 ; \mathrm{p}=0.828 ; \mathrm{p}=0.056$, respectively). However, in patients with hypertension, SCT and PPCT were significantly affected $(\mathrm{p}=0.010, \mathrm{r}=-0.297, \mathrm{p}=0.001, \mathrm{r}=-0.431$ respectively), while IOP and OPP $(p=0.227 ; p=0.534)$ were not affected. We think this is due to the cumulative effect of hypertension on cholesterol and atherosclerosis.

There was no relationship between cholesterol level of the patients and SCT, PPCT, IOP and OPP data $(\mathrm{p}=0.586$, $\mathrm{p}=286, \mathrm{p}=0.476, \mathrm{p}=0.217$; respectively). However, since cholesterol is significantly related to both the degree of ICA stenosis (Table 3 ) and blood pressure $(p=0.043, r=$ 0.193 ), it can be said to indirectly affect some eye parameters.

In non-smoking patients, a significant decrease was detected in PPCT data $(\mathrm{p}=0.001, \mathrm{r}=-0.404)$ although no relationship was found between the degree of carotid stenosis together with SCT, OPP and IOP data $(\mathrm{p}=0.068$, $\mathrm{p}=0.378, \mathrm{p}=0.542$ ). We think that this situation is random with the effect of confounding factors. However, in smokers, a significant relationship was detected between the degree of ICA stenosis together with SCT and PPCT data $(\mathrm{p}=0.006, \mathrm{r}=-0.51, \mathrm{p}=0.01, \mathrm{r}=-0.476)$. Although smoking does not appear to have a direct relationship with carotid stenosis and eye findings (Tables 3-5), we think that smokers have an indirect effect because of their high cholesterol and blood pressure, since they are more prone to atherosclerosis $(\mathrm{p}=0.033)$.

No significant association was found between age and SCT, PPCT, IOP, OPP $(\mathrm{p}=0.510, \mathrm{p}=0.726, \mathrm{p}=0.356$, $\mathrm{p}=0.703)$. The reason for this was, that the age distribution of the patients included according to carotid stenosis and coronary artery disease was not homogeneous, but mostly elderly patients.

When the data that can predict the SCT of patients were examined, it was observed that the changes in the degree of diastolic pressure and carotid stenosis significantly predicted SCT among all demographic features, but was low $\left(\mathrm{r}^{2}=0.114, \mathrm{p}=0.008\right.$, Durbin Watson=1.794, $\mathrm{f}=2.47$, Table 4). According to the degree of stenosis, when each group's parameters predicting SCT are evaluated among themselves; It was determined that the parameters of the mild, medium and control groups did not predict SCT significantly. In cases with severe stenosis 
Table I Analysis of the Difference and/or Relationship Status of Each of the Demographic Characteristics of the Patients Between the Groups

\begin{tabular}{|c|c|c|c|c|c|c|c|c|c|c|}
\hline & & \multicolumn{8}{|l|}{ Groups } & \multirow{3}{*}{$\begin{array}{l}\text { P. } \\
\text { value }\end{array}$} \\
\hline & & $\begin{array}{l}\text { Control } \\
(n=35)\end{array}$ & $\begin{array}{l}\text { Mild } \\
(n=26)\end{array}$ & $\begin{array}{l}\text { Moderate } \\
(n=27)\end{array}$ & $\begin{array}{l}\text { Severe } \\
(n=23)\end{array}$ & $\begin{array}{l}\text { Control } \\
(n=35)\end{array}$ & $\begin{array}{l}\text { Mild } \\
(n=26)\end{array}$ & $\begin{array}{l}\text { Moderate } \\
(n=27)\end{array}$ & $\begin{array}{l}\text { Severe } \\
(n=23)\end{array}$ & \\
\hline & & $\mathbf{n}$ & $\%$ & $\mathbf{n}$ & $\%$ & $\mathbf{n}$ & $\%$ & $\mathbf{n}$ & $\%$ & \\
\hline \multirow[t]{3}{*}{ Gender } & Female & 10 & 9 & 7 & 6.3 & 10 & 9 & 3 & 2.7 & \multirow[t]{3}{*}{$0.296^{\mathrm{a}}$} \\
\hline & Male & 25 & 22.5 & 19 & 17.1 & 17 & 15.3 & 20 & 18 & \\
\hline & \multicolumn{2}{|l|}{$P$ value } & \multicolumn{2}{|l|}{$0.248^{c}$} & \multicolumn{2}{|l|}{$0.496^{c}$} & \multicolumn{2}{|l|}{$0.370^{c}$} & $0.262^{c}$ & \\
\hline \multirow[t]{3}{*}{ Hypertension } & Unavailable & 14 & 12.6 & 12 & 10.8 & 7 & 6.3 & 4 & 3.6 & \multirow[t]{3}{*}{$0.116^{\mathrm{a}}$} \\
\hline & Available & 21 & 18.9 & 14 & 12.6 & 20 & 18 & 19 & 17.1 & \\
\hline & \multicolumn{2}{|l|}{$P$ value } & \multicolumn{2}{|l|}{$0.655^{c}$} & \multicolumn{2}{|l|}{$0.304^{c}$} & \multicolumn{2}{|l|}{$0.185^{c}$} & $0.803^{c}$ & \\
\hline \multirow[t]{3}{*}{ Smoking } & Unavailable & 29 & 26.1 & 19 & 17.1 & 20 & 18 & 15 & 13.5 & \multirow[t]{3}{*}{$0.499^{\mathrm{a}}$} \\
\hline & Available & 6 & 5.4 & 7 & 6.3 & 7 & 6.3 & 8 & 7.2 & \\
\hline & \multicolumn{2}{|l|}{$P$ value } & \multicolumn{2}{|l|}{$0.371^{c}$} & \multicolumn{2}{|l|}{$0.679^{c}$} & \multicolumn{2}{|l|}{$0.366^{\mathrm{c}}$} & $0.817^{c}$ & \\
\hline & & Median & Min-Max & Median & Min-Max & Median & Min-Max & Median & Min-Max & \\
\hline Cholesterol & & 210 & $120-260$ & 175 & $120-270$ & 230 & $120-282$ & 245 & |35-296 & $0.007^{b}$ \\
\hline \multirow{2}{*}{\multicolumn{2}{|c|}{$P$ and $r$ value }} & $P$ & $r$ & $P$ & $r$ & $P$ & $r$ & $\mathrm{P}$ & $r$ & \\
\hline & & $0.181^{d}$ & 0.231 & $0.279^{d}$ & 0.221 & $0.012^{d}$ & 0.479 & $0.816^{\mathrm{d}}$ & 0.051 & \\
\hline \multirow{2}{*}{\multicolumn{2}{|c|}{ Age }} & 71 & $65-80$ & 71 & $60-82$ & 73 & $64-80$ & 75 & $65-80$ & \multirow[t]{3}{*}{$0.560^{\mathrm{b}}$} \\
\hline & & $P$ & $r$ & $\mathrm{P}$ & $r$ & $\mathrm{P}$ & $r$ & $\mathrm{P}$ & $r$ & \\
\hline$P$ and $r$ value & & $0.255^{\mathrm{d}}$ & 0.197 & $0.620^{d}$ & 0.102 & $0.542^{\mathrm{d}}$ & -0.123 & $0.849^{d}$ & 0.042 & \\
\hline
\end{tabular}

Notes: $p^{a}$, Pearson chi-square test; $p^{b}$, Kruskal-Wallis test; $p^{c}$, Mann-Whitney U-test; $p^{d}$, Spearman correlation test.

(70-99\%); It was determined that SCT can predict $72.8 \%$ and this is found significantly $\left(\mathrm{p}=0.001, \mathrm{~F}=7132, \mathrm{r}^{2}=0.728\right.$, Durbin-Watson=1566). In the model, it was determined that carotid stenosis, cholesterol, systolic and diastolic blood pressure predicted SCT significantly, smoking and age did not affect (Table 4).

When the demographic data that could predict the PPCT of the patients were examined, it was seen that the degree of carotid stenosis predicted PPCT significantly, but other parameters were not significant. PPCT has been found to be associated with cholesterol, as well as carotid stenosis. $\left(p=0.001, r^{2}=0.264 \mathrm{~F}=7537\right.$, Durbin Watson $=$ 1.92, Table 5).

\section{Discussion}

In our study, a significantly lower choroid thickness was determined in the patients with serious with severe carotid stenosis in comparison to the other groups. Sayin et al also examined the thickness of SCT in cases with carotid stenosis, however, in their study, they did not find a relationship between the degree of stenosis and SCT. ${ }^{10}$ In our study, as the severity of ICA stenosis increased, we observed that SCT decreased by $8 \%$ and PPCT decreased by $22.4 \%$, which was statistically significant (Table 3 ).

The prevalence rate of asymptomatic extracranial carotid artery disease ( $>50 \%$ stenosis) ranges between $1.5 \%$ and $9 \%$ in population-based studies. ${ }^{11,12}$ Blood supply to the eyes is mainly provided through the carotid arteries. Therefore, obstructive ICA diseases have an important role in the development of ocular arterial ischemic events. ${ }^{4,11}$ However, it has also been reported that more than $90 \%$ stenosis in the ICA is required for ocular symptoms to occur. ${ }^{4}$ It has been shown in many articles that ocular circulation is affected in patients with ICA stenosis. Often, the presence of ICA stenosis is thought to be related to the symptoms in the ipsilateral eye. ${ }^{4,13}$ There is no apparent hemodynamic change in the eye until the ICA lumen 
Table 2 A Significant Difference Was Found Between SCT and PPCT Data of Groups Increased Carotid Artery Stenosis. In Post Hoc Analysis, This Difference Was Observed Between the Severe Stenosis Group and the Control and Mild Stenosis Groups. However, There Was No Difference Between the IOP and OPP Data of the Groups

\begin{tabular}{|c|c|c|c|c|c|c|c|c|c|}
\hline & \multicolumn{8}{|l|}{ Groups } & \multirow[t]{3}{*}{ p-value } \\
\hline & \multicolumn{2}{|l|}{ Control } & \multicolumn{2}{|l|}{ Mild } & \multicolumn{2}{|c|}{ Moderate } & \multicolumn{2}{|l|}{ Severe } & \\
\hline & Median & Min-Max & Median & Min-Max & Median & Min-Max & Median & Min-Max & \\
\hline SCT & 306 & $223-412$ & 302 & $216-412$ & 298 & $210-431$ & 245 & $206-322$ & 0.003 \\
\hline PPCT & 138 & $128-146$ & 137.6 & $|32-| 48$ & 136.4 & $128-148$ & 128.6 & $120.3-138$ & 0.001 \\
\hline IOP & 14 & $11-18$ & 14 & $11-18$ & 14 & $12-18$ & 14 & $12-16$ & 0.935 \\
\hline OPP & 43.78 & $35.3-52.5$ & 43.6 & $35.3-50.45$ & 43.12 & $37.6-50$ & 43.56 & $37.5-50$ & 0.519 \\
\hline
\end{tabular}

Note: p, Kruskal-Wallis H-test.

occlusion reaches $70-90 \%$. However, central retinal perfusion may decrease by $50 \%$ when the carotid stenosis degree reaches $90 \%$. If the occlusion exceeds $90 \%$ or is nearly complete, perfusion in the ophthalmic artery can be achieved only from the branches of the external carotid artery. This way, in case of steal syndrome, ocular perfusion may be inadequate. ${ }^{13,14}$ In a study by Lieb et al, they showed that the blood flow rates of the ophthalmic artery and temporal short posterior ciliary arteries decreased in patients with ICA occlusion. ${ }^{15}$ In patients with severe ICA stenosis, severe hemodynamic changes are observed in the central retinal artery, posterior ciliary artery and ophthalmic artery before ocular ischemic syndrome occurs. ${ }^{16}$ They found that in patients with ICA stenosis by Lyons-Wait et al, hemodynamic
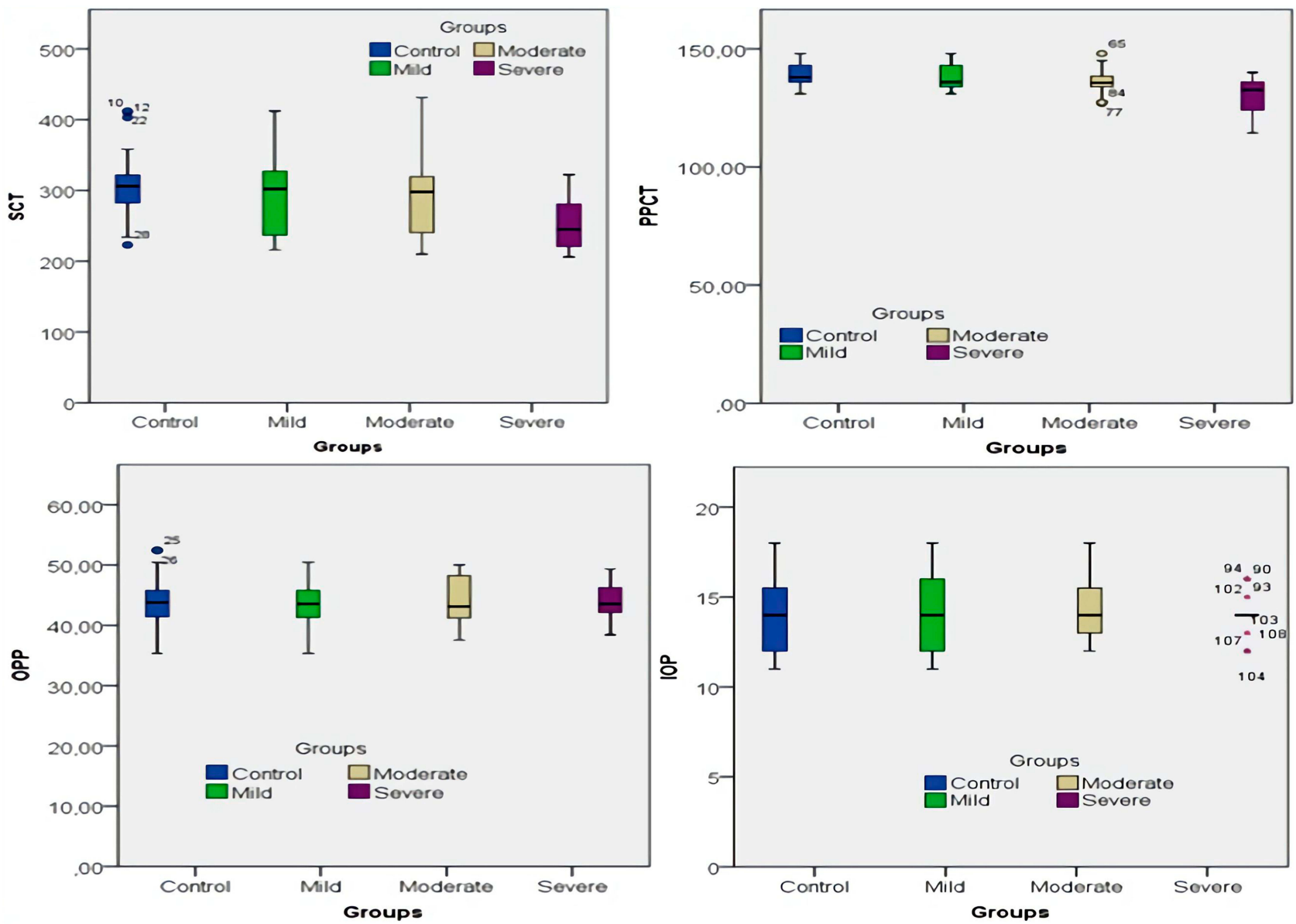

Figure 3 Distribution of SCT, PPCT, IOP, OPP values of groups according to the degree of carotid artery stenosis. 
Table 3 Parameters and Significance Levels That Can Predict ICA Stenosis Significantly are Seen. The Table Also Shows the Relationship Status of Each Parameter with Carotid Stenosis

\begin{tabular}{|c|c|c|c|c|c|c|c|c|c|}
\hline \multicolumn{8}{|c|}{ Coefficients $^{\mathrm{a}}$} & \multirow{2}{*}{\multicolumn{2}{|c|}{ Correlations }} \\
\hline \multicolumn{2}{|c|}{ Model } & \multirow[t]{2}{*}{ Odds Ratio } & \multirow[t]{2}{*}{ Std. Error } & \multirow[t]{2}{*}{$\mathbf{t}$} & \multirow[t]{2}{*}{ Sig. } & \multicolumn{2}{|c|}{$95.0 \% \mathrm{Cl}$ for Odds } & & \\
\hline & & & & & & Lower & Upper & $\mathbf{r}$ & $\mathbf{p}^{\mathbf{b}}$ \\
\hline \multirow[t]{9}{*}{1} & (Constant) & 261,326 & 73,097 & 3575 & 0.001 & 116,339 & 406,312 & & \\
\hline & Cholesterol & 0.119 & 0.043 & 2773 & 0.007 & 0.034 & 0.204 & 0.325 & 0.001 \\
\hline & SCT & -0.069 & 0.038 & -1842 & 0.068 & -0.144 & 0.005 & 0.283 & 0.003 \\
\hline & PPCT & -1762 & 0.352 & -5003 & 0.000 & -2461 & -1064 & 0.473 & 0.001 \\
\hline & IOP & 1621 & 1545 & 1049 & 0.297 & -1444 & 4686 & 0.042 & 0.661 \\
\hline & OPP & 0.797 & 1150 & 0.693 & 0.490 & -1484 & 3077 & 0.093 & 0.332 \\
\hline & Age & 0.097 & 0.378 & 0.258 & 0.797 & -0.652 & 0.847 & 0.126 & 0.186 \\
\hline & Systolic blood pressure & -0.435 & 0.372 & $-|17|$ & 0.244 & -1173 & 0.302 & 0.072 & 0.450 \\
\hline & Diastolic blood pressure & 0.108 & $0 ., 543$ & 0.199 & 0.843 & -0970 & 1186 & 0.146 & 0.127 \\
\hline
\end{tabular}

Notes: ${ }^{\mathrm{a}}$ Dependent Variable: Carotid stenosis, $\mathrm{p}^{\mathrm{b}}$, Spearman Correlation test.

Abbreviations: DP, diastolic pressure; SP, systolic pressure.

Table 4 Considering Only Cases with Severe Carotid Stenosis (70-99\%), The Parameters Predicting SCT are; Severe Carotid Stenosis, Cholesterol, Systolic and Diastolic Blood Pressure

\begin{tabular}{|c|c|c|c|c|c|c|c|c|c|}
\hline \multicolumn{8}{|c|}{ Coefficients $^{a}$} & \multirow{2}{*}{\multicolumn{2}{|c|}{ Correlations }} \\
\hline \multicolumn{2}{|c|}{ Model } & \multirow[t]{2}{*}{ Odds Ratio } & \multirow[t]{2}{*}{ Std. Error } & \multirow[t]{2}{*}{$\mathbf{t}$} & \multirow[t]{2}{*}{$\mathbf{p}^{\mathbf{a}}$} & \multicolumn{2}{|c|}{ 95.0\% $\mathrm{Cl}$ for Odds } & & \\
\hline & & & & & & Lower & Upper & $\mathbf{r}$ & $\mathbf{p}^{\mathbf{b}}$ \\
\hline \multirow[t]{7}{*}{1} & (Constant) & $-28,719$ & 152,450 & -0.188 & 0.853 & $-351,898$ & 294,460 & & \\
\hline & Carotid stenosis & 0.969 & 0.463 & 2091 & 0.053 & -0.013 & 1952 & -0.355 & 0.097 \\
\hline & Cholesterol & 0.493 & 0.132 & $374 I$ & 0.002 & 0.214 & $0 / 773$ & -0.532 & 0.009 \\
\hline & Smoking & $-|4| 3 \mid$, & 11,076 & -1276 & 0.220 & $-37,611$ & 9349 & -0.014 & 0.950 \\
\hline & AGE & -1414 & 1099 & -1286 & 0.217 & -3744 & 0.917 & 0.035 & 0.874 \\
\hline & $\mathrm{SP}$ & 3004 & 0.916 & 3280 & 0.005 & 1062 & 4946 & $0.07 I$ & 0.749 \\
\hline & $\mathrm{DP}$ & -2102 & 1003 & -2096 & 0.052 & -4227 & 0.023 & -0.522 & 0.011 \\
\hline
\end{tabular}

Notes: ${ }^{\mathrm{a}}$ Groups $=$ Severe, $\mathrm{p}^{\mathrm{a}}$, Dependent Variable, SCT $\mathrm{p}^{\mathrm{b}}$, Spearman Correlation test.

Abbreviations: DP, diastolic pressure; SP, systolic pressure.

Table 5 Distribution of Parameters Predicting PPCT. The Table Also Shows the Relationship Status of the Measurements

\begin{tabular}{|c|c|c|c|c|c|c|c|c|c|}
\hline \multicolumn{8}{|c|}{ Coefficients $^{\mathrm{a}}$} & \multirow{2}{*}{\multicolumn{2}{|c|}{ Correlations }} \\
\hline \multicolumn{2}{|c|}{ Model } & \multirow[t]{2}{*}{ Odds Ratio } & \multirow[t]{2}{*}{ Std. Error } & \multirow[t]{2}{*}{$\mathbf{t}$} & \multirow[t]{2}{*}{$\mathbf{p}$} & \multicolumn{2}{|c|}{$95 \% \mathrm{Cl}$ for Odds } & & \\
\hline & & & & & & Lower & Upper & $\mathbf{r}$ & $\mathbf{p}^{\mathbf{b}}$ \\
\hline \multirow[t]{6}{*}{ I } & (Constant) & 156,106 & 11,178 & 13,965 & 0.001 & 133,942 & 178,27 & & \\
\hline & Age & -0.01 & 0.096 & -0.101 & 0.92 & -0.199 & 0.18 & -0.078 & 0.417 \\
\hline & Carotid stenosis & -0.114 & 0.022 & -5186 & 0.001 & -0.158 & $-0.07 \mid$ & -0.473 & 0.001 \\
\hline & Cholesterol & -0.005 & 0.011 & -0.458 & 0.648 & -0.028 & 0.017 & -0.218 & 0.021 \\
\hline & $S_{p}$ & -0.066 & 0.071 & -0.923 & 0.358 & -0.207 & 0.075 & -0.126 & 0.186 \\
\hline & Dp & -0.069 & 0.097 & -0.714 & 0.477 & -0.262 & 0.123 & -0.134 & 0.162 \\
\hline
\end{tabular}

Notes: ${ }^{a}$ Dependent Variable: PPCT, Dp, Diastolic pressure Sp, Systolic pressure $\mathrm{p}^{\mathrm{b}}$, Spearman correlation.

changes, including retinal vascular occlusions, increased 1.8fold compared to healthy people. They also showed that $5 \%$ of cases with severe carotid stenosis may have ocular hemodynamic abnormalities. ${ }^{6}$ In our study, we did not measure ocular flow rates in patients with asymptomatic but severe ICA stenosis. However, we think that the significant thinning 
detected in choroidal thickness is a sign of ocular ischemia. Considering only cases with severe carotid stenosis (70-99\%), SCT was observed to predict not only carotid stenosis but also blood pressure and cholesterol level (Table 4).

Choroid blood flow and oxygen pressure are known to be significantly higher compared to other organs in the body. ${ }^{2}$ In this context, the relationship between choroidal thickness and choroidal circulation has been the subject of important research in the past. ${ }^{7}$ Utsugi et al reported that there was a significant hypoperfusion in the intracoroidal circulation in case of severe internal carotid stenosis. ${ }^{17}$ Wang et al also suggested that as the degree of ICA stenosis increases, ocular hemodynamic changes worsen in relation to this. ${ }^{18}$ On the other hand, Akçay et al concluded that SCT is thicker in the case of internal carotid stenosis. In their study, they explained that the reason for this is that stenosis-related ischemia and metabolic events cause the collateral circulation to open so that the choroid becomes thicker by the compensation mechanism. ${ }^{19}$ In our study, we found that SCT and PPCT values were moderately associated with increased carotid artery stenosis, and both predicted the severity of carotid stenosis, along with cholesterol, by $33.7 \%$, but IOP and OPP were not associated with carotid stenosis (Table 3). Thinning in both PPCT and SCT may be indicative of a decrease in ocular blood flow at these predicted rates.

Studies have reported that choroidal thickness is affected by age, axial length, and chorioretinal disorders. ${ }^{20}$ A thin choroid is characteristic especially in those with high myopia, diabetic retinopathy and pseudoexfoliation disorders. ${ }^{20,21}$ In our study, besides these factors, systemic diseases that are likely to produce variable results in studies with choroid thickness were also excluded.

Gok et al systemic hypertension has been shown to affect subfoveal choroidal thickness. ${ }^{22}$ In our study, blood pressure was the most important predictor of SCT and was held responsible for a decrease of approximately two-fold choroid thickness. However, it was suggested that there was an association between a thinner choroid and cigarette smoking $^{23}$ and systemic essential hypertension. ${ }^{24}$ Subfoveal choroid thickness was reported to be thicker in hypercholesterolemia. ${ }^{25}$ In our study, we determined that hypercholesterolemia and ICA stenosis reduced choroidal thickness both directly and independently. Although hypertension had no effect on carotid stenosis, it directly reduced choroidal thickness. The increase in cholesterol level significantly increased the degree of carotid stenosis and indirectly influenced choroidal thickness. We found that smoking has a cumulative effect by increasing blood pressure, cholesterol and carotid stenosis, although it does not have a direct effect on choroid thickness. Smoking had no effect on IOP and OPP.

Ahmad et al, measured SCT to be thinner in coronary artery patients and stated that atherosclerotic process might affect choroid which was an organ with high blood flow. ${ }^{26}$ However, in our study, the effect of coronary artery disease was eliminated as we formed the control group only from patients with coronary artery disease. In addition, the choroid thickness of our control group was similar to that of normal individuals. In the study performed by Ahmad et al, coronary artery disease patients were investigated but it was not stated whether the ICA stenosis was present or not in these patients. We found that the difference was associated with the degree of ICA stenosis. In addition to this, risk factors such as cholesterol, hypertension were not investigated either In our study, we can say that coronary artery disease is not alone in affecting SCT and PPCT.

\section{Limitation}

Cross-sectional design and lack of long-term follow-up results were the most important limitations of our study. While stenosis continues, long-term follow-up is necessary to determine whether the thinning in the choroid has sensitivity and specificity. In addition, thinning of the choroid occurs as a result of a multifactorial effect. It is quite difficult to isolate all of them. The second important limitation was the manual transmission of all identities of the Bruch membrane and the inner scleral border, as Heidelberg Spectral optical coherence tomography equipment did not provide automatic segmentation of the choroid. The third important limitation is to not consider the types of drugs used by patients with controlled hypertension during the study. Although we have detected the effect of changes in blood pressure on SCT, the difference in the diurnal rhythm may cause differences in the results of patients.

\section{Conclusion}

In conclusion, we found a significant thinning of subfoveal and peripapillary choroid thickness (SCT and PPCT) in patients with severe ICA stenosis, although it was asymptomatic. This finding may be important for indicating ocular blood flow. Choroid thickness is be an indirect marker of choroid blood flow. From these findings, we can say that choroid blood flow is decreased in patients 
with asymptomatic severe ICA stenosis. However, complications arising from the decrease in choroidal thickness, and whether the reduction continues, and long follow-up results, are unknown in these patients. Since our study is a cross-sectional study, it does not include long follow-up results. However, chronic ocular blood flow reduction may result in important outcomes for visual prognosis. In the light of these findings, while deciding the surgical treatment of patients with asymptomatic ICA stenosis, a decrease in choroid thickness may also be among the indications. On the other hand, it should be kept in mind that ICA stenosis may also be present in patients with choroidal thinning. As a result, we think that there may be many factors affecting the SCT and PPCT thicknesses of the patients, and if more factors are investigated in future studies, different results can be obtained due to the interaction between the factors.

\section{Funding}

No financial support was received for this submission.

\section{Disclosure}

None of the authors has conflict of interest with the submission.

\section{References}

1. Takahashi K, Muraoka K, Kishi S, Shimizu K. Watershed zone in the human peripheral choroid. Ophthalmology. 1996;103(2):336-342. doi:10.1016/s0161-6420(96)30695-7

2. Nickla DL, Wallman J. The multifunctional choroid. Prog Retin Eye Res. 2010;29(2):144-168. doi:10.1016/j.preteyeres.2009.12.002

3. Dugan J, Green W. Ophthalmologic manifestations of carotid occlusive disease. Eye. 1991;5(2):226-238. doi:10.1038/eye.1991.38

4. Drakou AA, Koutsiaris AG, Tachmitzi SV, Roussas N, Tsironi E, Giannoukas AD. The importance of ophthalmic artery hemodynamics in patients with atheromatous ICA disease. Int Angiol. 2011;30 (6):547-554

5. Lawrence PF, Oderich GS. Ophthalmologic findings as predictors of carotid artery disease. Vasc Endovascular Surg. 2002;36(6):415-424. doi: $10.1177 / 153857440203600602$

6. Lyons-Wait VA, Anderson SF, Townsend JC, De Land P. Ocular and systemic findings and their correlation with hemodynamically significant carotid artery stenosis: a retrospective study. Optom Vis Sci. 2002;79(6):353-362. doi:10.1097/00006324-200206000-00008

7. Kim M, Kim SS, Kwon HJ, Koh HJ, Lee SC. Association between choroidal thickness and ocular perfusion pressure in young, healthy subjects: enhanced depth imaging optical coherence tomography study. Invest Ophthalmol Vis Sci. 2012;53(12):7710-7717. doi:10.1167/ iovs.12-10464

8. Spaide RF, Koizumi H, Pozzoni MC. Enhanced depth imaging spectral-domain optical coherence tomography. [Published correction appears in Am J Ophthalmol. 2009 Aug;148(2):325. Pozonni, Maria C [Corrected to Pozzoni, Maria C]].. Am J Ophthalmol. 2008;146 (4):496-500. doi:10.1016/j.ajo.2008.05.032
9. Grant EG, Benson CB, Moneta GL, et al. Carotid artery stenosis: gray-scale and doppler US diagnosis - society of radiologists in ultrasound consensus conference. Radiology. 2003;229(2):340-346. doi:10.1148/radiol.2292030516

10. Sayin N, Kara N, Uzun F, Akturk IF. A quantitative evaluation of the posterior segment of the eye using spectral-domain optical coherence tomography in carotid artery stenosis: a pilot study. Ophthalmic Surg Lasers Imaging Retina. 2015;46(2):180-185. doi:10.3928/2325816020150213-20

11. Willeit J, Kiechl S. Prevalence and risk factors of asymptomatic extracranial carotid artery atherosclerosis. A population-based study. Arterioscler Thromb. 1993;13(5):661-668. doi:10.1161/01.atv.13.5.661

12. Prati P, Vanuzzo D, Casaroli M, et al. Prevalence and determinants of carotid atherosclerosis in a general population. Stroke. 1992;23 (12):1705-1711. doi:10.1161/01.str.23.12.1705

13. Yamamoto T, Mori K, Yasuhara T, et al. Ophthalmic artery blood flow in patients with internal carotid artery occlusion. $\mathrm{Br} J$ Ophthalmol. 2004;88(4):505-508. doi:10.1136/bjo.2003.025809

14. Caplan LR. Caplan's Stroke, a Clinical Approach. 4th ed. Philadelphia, PA, USA: Saunders; 2009.

15. Lieb WE, Flaharty PM, Sergott RC, et al. Color doppler imaging provides accurate assessment of orbital blood flow in occlusive carotid artery disease. Ophthalmology. 1991;98(4):548-552. doi:10. 1016/s0161-6420(91)32257-7

16. Mawn LA, Hedges TR 3rd, Rand W, Heggerick PA. Orbital color doppler imaging in carotid occlusive disease. Arch Ophthalmol. 1997;115(4):492-496. doi:10.1001/archopht.1997.01100150494007

17. Utsugi N, Takahashi K, Kishi S. Choroidal vascular occlusion in internal carotid artery obstruction. Retina. 2004;24(6):915-919. doi:10.1097/00006982-200412000-00012

18. Wang H, Li H, Zhang X, Qiu L, Wang Z, Wang Y. Ocular image and haemodynamic features associated with different gradings of ipsilateral internal carotid artery stenosis. J Ophthalmol. 2017;2017:1842176. doi:10.1155/2017/1842176

19. Akçay Bİ, Kardeş E, Maçin S, et al. Evaluation of subfoveal choroidal thickness in internal carotid artery stenosis. $J$ Ophthalmol. 2016;2016:5296048. doi:10.1155/2016/5296048

20. Goldenberg D, Moisseiev E, Goldstein M, et al. Enhanced depth imaging optical coherence tomography: choroidal thickness and correlations with age, refractive error, and axial length. Ophthalmic Surg Lasers Imaging. 2012;43(4):296-301. doi:10.3928/1542887720120426-02

21. Turan-Vural E, Yenerel N, Okutucu M, Yildiz E, Dikmen N. Measurement of subfoveal choroidal thickness in pseudoexfoliation syndrome using enhanced depth imaging optical coherence tomography. Ophthalmologica. 2015;233(3-4):204-208. doi:10.1159/0003 71899

22. Gök M, Karabas VL, Emre E, Aksar AT, Aslan MS, Ural D. Evaluation of choroidal thickness via enhanced depth-imaging optical coherence tomography in patients with systemic hypertension. Indian J Ophthalmol. 2015;63(3):239-243. doi:10.4103/0301-4738.156928

23. Sigler EJ, Randolph JC, Calzada JI, Charles S. Smoking and choroidal thickness in patients over 65 with early-atrophic age-related macular degeneration and normal. Eye (Lond). 2014;28(7):838-846. doi: 10.1038/eye.2014.100

24. Akay F, Gundogan F, Yolcu U, Toyran S, Uzun S. Choroidal thickness in systemic arterial hypertension. Eur J Ophthalmol. 2016;26 (2):152-157. doi:10.5301/ejo.5000675

25. Wong IY, Wong RL, Zhao P, Lai WW. Choroidal thickness in relation to hypercholesterolemia on enhanced depth imaging optical coherence tomography. Retina. 2013;33(2):423-428. doi:10.1097/IAE.0b $013 \mathrm{e} 3182753 \mathrm{~b} 5 \mathrm{a}$

26. Ahmad M, Kaszubski PA, Cobbs L, Reynolds H, Smith RT, Paul F. Choroidal thickness in patients with coronary artery disease. PLoS One. 2017;12(6):e0175691. doi:10.1371/journal.pone.0175691 


\section{Publish your work in this journal}

Clinical Ophthalmology is an international, peer-reviewed journal covering all subspecialties within ophthalmology. Key topics include: Optometry; Visual science; Pharmacology and drug therapy in eye diseases; Basic Sciences; Primary and Secondary eye care; Patient Safety and Quality of Care Improvements. This journal is indexed on PubMed
Central and CAS, and is the official journal of The Society of Clinical Ophthalmology (SCO). The manuscript management system is completely online and includes a very quick and fair peer-review system, which is all easy to use. Visit http://www.dovepress.com/ testimonials.php to read real quotes from published authors.

Submit your manuscript here: https:/www.dovepress.com/clinical-ophthalmology-journal 